\title{
Temperature Field and Thermal Stress Analyses of High-Speed Train Brake Disc Under Pad Variations
}

\author{
Chen Jiguang ${ }^{*}$ and Gao Fei
}

State Key Lab of Continuous Extrusion, Dalian Jiaotong University, P.O. Box 351 No.794 Huang He Road, 116028, Dalian, China

\begin{abstract}
Transient heat transfer analysis of disc brake has been performed to find out an ideal shape of pad geometry. The analysis has taken frictional heat between brake disc and pads as heat flux onto the friction surface, the disc and the pad's temperature fields then were explored involving thermal conduction, forced convection and surface radiation effects. The disc thermal expansion stress was then acquired by quasi-static analysis using its temperature of aforesaid heat transfer analysis. Five prototypes of pad designs with geometry and volume variations were implemented for analytical comparison. Both pads and disc are required to have lower and uniform temperature field and thermal stress. The results uncover that heat conduction is domination in heat dissipation progress during braking, and big volume pad is cooler. Pad volume has more impact to heat transfer procedure and temperature gradient than pad geometry variation does. The design has 10 triangle pads is considered to be an ideal candidate. Its maximum disc temperature and thermal stress are the least among the five designs.
\end{abstract}

Keywords: Brake pad, heat transfer, numerical simulation, optimization, ventilated disc.

\section{INTRODUCTION}

Started from the Japanese Shinkansen in 1964, highspeed train was reported to run fast and faster in commercial services. Some modern high-speed train capacities are listed in Table 1 (Wikipedia). While the speed increasing, the brake system must be stronger to meet the rapid growth of kinetic energy. It faces tougher demands on energy dissipation and safety level requirements.

Table 1. World major high speed trains capacity.

\begin{tabular}{|c|c|c|c|c|}
\hline & $\begin{array}{c}\text { Japan } \\
\text { Shinkansen }\end{array}$ & $\begin{array}{c}\text { France } \\
\text { TGV }\end{array}$ & $\begin{array}{c}\text { Germany } \\
\text { ICE }\end{array}$ & $\begin{array}{c}\text { China } \\
\text { CRH }\end{array}$ \\
\hline \hline Start year & 1964 & 1980 & 1989 & 2002 \\
\hline $\begin{array}{c}\text { Operating } \\
\text { Speed }\end{array}$ & $240-320 \mathrm{~km} / \mathrm{h}$ & $270-320 \mathrm{~km} / \mathrm{h}$ & $200-300 \mathrm{~km} / \mathrm{h}$ & $200-350 \mathrm{~km} / \mathrm{h}$ \\
\hline $\begin{array}{c}\text { Speed Record } \\
\text { \& Year }\end{array}$ & $\begin{array}{c}443 \mathrm{~km} / \mathrm{h} \\
1996\end{array}$ & $\begin{array}{c}575 \mathrm{~km} / \mathrm{h} \\
2007\end{array}$ & $\begin{array}{c}406 \mathrm{~km} / \mathrm{h} \\
1988\end{array}$ & $\begin{array}{c}486 \mathrm{~km} / \mathrm{h} \\
2010\end{array}$ \\
\hline
\end{tabular}

Disc brakes must dissipate large amounts of heat energy at high rates. Phenomena such as thermal banding [1], hotspotting [2] and thermal cracking [3] are thought to be main reasons cause disc failure. These premature failures relate to most critical brake design parameters, such as the braking energy, heat partition, friction coefficient, geometries and dimensions of the brake components, materials of the disc and the pad, even the contact pressure distribution [4].

*Address correspondence to this author at the State Key Lab of Continuous Extrusion, Dalian Jiaotong University, P.O. Box 351 No.794 Huang He Road, 116028, Dalian, China; Tel: 86-411-84105550;

Fax: 86-411-84106382; E-mail: chenjg@djtu.edu.cn
Brake performance also must be guaranteed with extensive testing under extreme conditions. Brake system needs to be highly optimized to prevent the disc from overheating, which reduces braking efficiency or even system failure. Attempt in this paper is to perform optimal design of the pad structure by focusing on the temperature filed and disc thermal stress. The approach of this study is to compare the disc and the pad's temperature fields under different pad geometries to discover a lower operational temperature design. The temperature field is acquired by transient heat transfer analysis.

\section{LITERATURE REVIEW}

Experimental and numerical approaches of managing heat transfer and minimizing operational temperatures to avoid premature failure have been performed by lots of researches. Finite element analysis (FEA) is widely employed for performance estimation in earlier design of a brake system. Numerical methods were implemented to calculate braking energy, power and temperatures in brakes under transient and steady-state conditions, included classical [5], finite element [6] and computational fluid dynamics (CFD) [7] analyses. The mainstream FEA packs included ANSYS [8], ABAQUS [9], COMSOL [10], IDEAS [11], LS-DYNA [12], MD NASTRAN [13] have been applied.

Heat generation and partition at friction interface, thermal contact resistance, conduction, convection and radiation cooling, thermal deformations and stresses, and related failure mechanisms were deeply discussed for brakes with solid or ventilated disc. Adamowicz et al. [14] dealt with the finite element modeling of the frictional heating process in disc brakes to study the temperature and stress 
distributions during operation, they noticed rapid temperature change induced thermal stresses. Yevtushenko et al. [15] adopted two different disc brake systems for the FE analysis. They dug out the influence of nine experimental and theoretical formulas for the heat partition ratio. Meresse et al. [16] focused on the local heat fluxes on disc during braking. The generated heat and temperature field were identified with an inverse heat conduction method coupled to temperature measurements inside the disc. They discussed the influence of the braking conditions on heat re-partition and surface temperature. Day et al. [17] described how the thermal effects of interface pressure distribution might be divided into bulk temperature effects. Dufrenoy [18] proposed a macro structural model of the thermo mechanical behavior of the disc brake. Contact surface variations, distortions and wear have been taken into account to give predictions of the thermal gradients varying with time.

Disc structure optimization attracted more researchers. Tirovic [19] used CFD simulation for an innovative disc with radial vanes and circumferential pillars proved to be successful in operation and achieved energy efficiency improvements. Nejat et al. [20] proposed a method to enhance the heat transfer of ventilated brake discs using modified vanes. The heat transfer coefficient of the brake disc's ventilation was estimated by a CFD result. Duzgun [21] studied the thermal behaviors of ventilated brake discs using three different configurations at continuous brake conditions in terms of heat generation and thermal stresses with FEA method. Munisamy et al. [22] revealed the potential heat transfer enhancements in a ventilated brake disc by varying the geometrical parameters of the blades inside the flow passage.

Three kinds of pads were tested by Panier et al. [2] for hot spots occurrence investigation. They studied the pad stiffness and pad contact length on hot spots developments. Moses et al. [23] investigated the heat generation and dissipation in a disc brake of two different brake pad materials during braking with COMSOL. Sujatha et al. [24] examined three geometrical modifications of the brake pad for reducing the propensity of squeal generation in the brake system. These modifications included utilizing chamfer configurations, changing back plate thickness and changing friction material thickness.
Pad geometry changes definitely will improve the brake performance $[2,24]$. We delicately changed the shape and arrangement of the pads, formed several pad geometries. After took the kinetic energy as frictional surface heat source $[22,23]$ in the transient heat transfer analysis, the conductive, convective and radiative dissipated heat were investigated for comparing, the capacities of heat energy generation, transfer and dissipation was fully discussed. Finally, temperature filed was compared to find out an idea pad structure.

\section{THEORETICAL ANALYSIS ON THE TRANSIENT HEAT IN BRAKING}

The train brake system employs both axle and wheel mounted disc brakes. The frictional pair consists of low ventilated cast steel disc and sinter brake pads, both conform to the UIC standards.

The material properties of the disc and the pads are showed in Table 2.

Table 2. Material properties of the disc and the pad.

\begin{tabular}{|c|c|c|}
\hline Name & Disc & Pad \\
\hline \hline Heat capacity, $C_{p}, \mathrm{~J} /(\mathrm{kg} \cdot \mathrm{K})$ & 475 & 405 \\
\hline Thermal conductivity, $k, \mathrm{~W} / \mathrm{m} \cdot \mathrm{K}$ & 44.5 & 40.4 \\
\hline Coefficient of thermal expansion, $\alpha, \mathrm{K}^{-1}$ & $12.3 \mathrm{e}-6$ & $11.3 \mathrm{e}-6$ \\
\hline Density, $\rho, \mathrm{kg} / \mathrm{m}^{3}$ & 7850 & 5550 \\
\hline Young's modulus, $E$, Pa & $200 \mathrm{e} 9$ & $100 \mathrm{e} 9$ \\
\hline Poisson's ratio, $p$ & 0.33 & 0.30 \\
\hline
\end{tabular}

\subsection{Geometry of Brake Components}

The 3D model of the axle mounted disc brake has been constructed according to the Chinese standard. The diameter of the real disc is $640 \mathrm{~mm}$ and thickness is $80 \mathrm{~mm}$ with ventilate groves inside (Fig. 1, Left). To simplify the numerical model, we only considered the pads and the carrier plate, excluded the pad holder. The pad's thickness is $30 \mathrm{~mm}$ and the carrier plate's thickness is $12 \mathrm{~mm}$. Half of the brake was modeled due to symmetry (Fig. 1, Right).
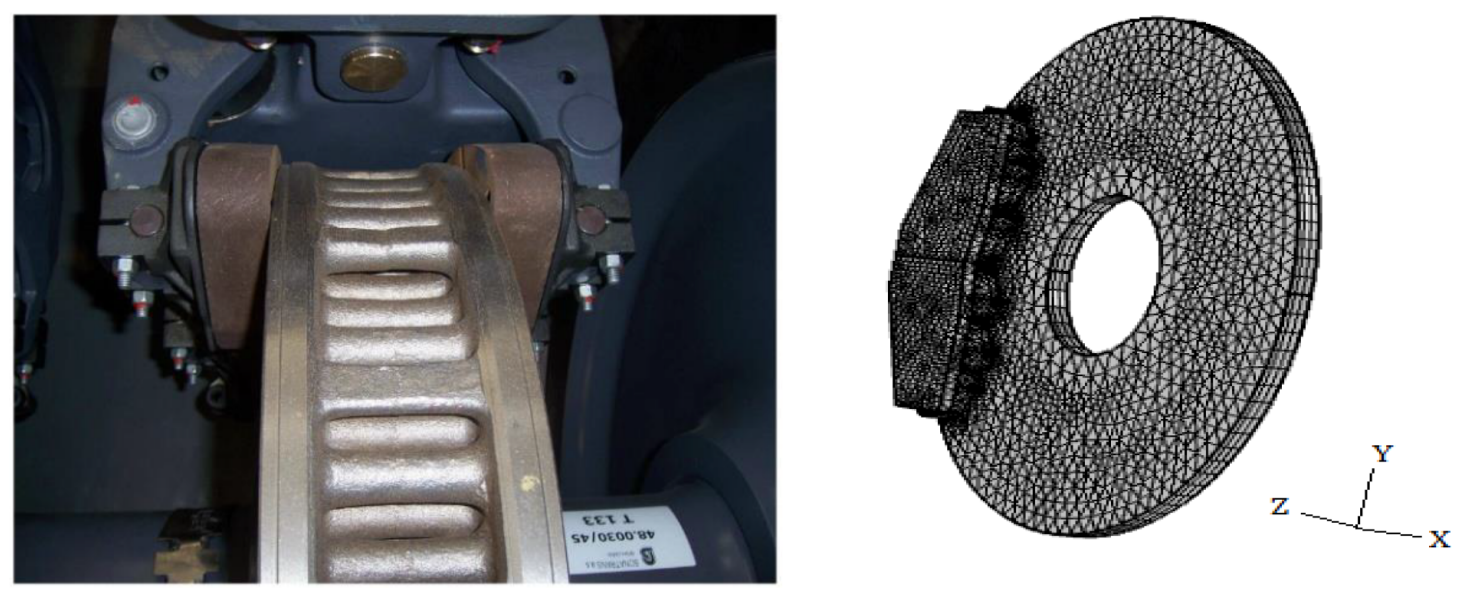

Fig. (1). Disc brake with low ventilated cast steel disc and sinter pads (Left) and its simplified numerical model (Right). 
Table 3. Designs of pad's shapes and geometrical parameters.

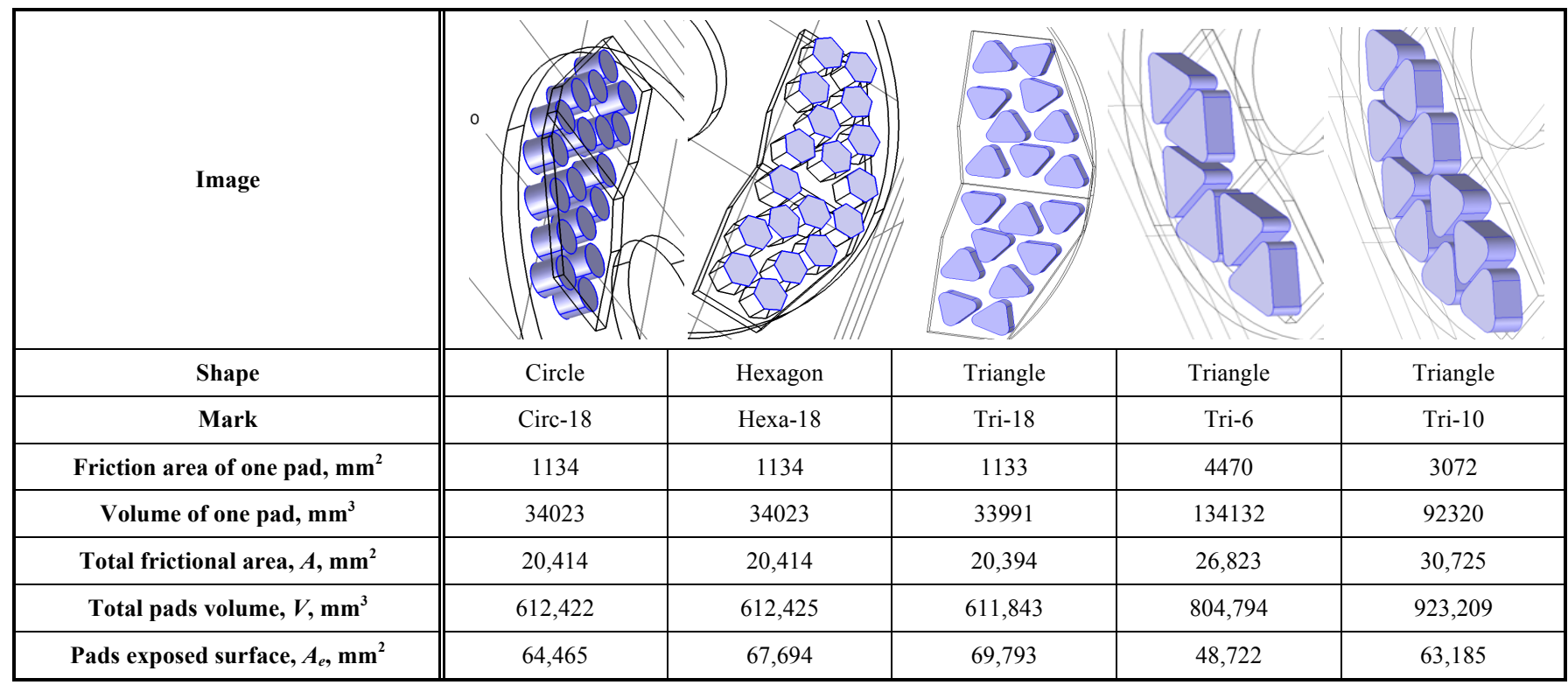

Five qualified designs of the pad geometries are listed in Table 3. The Circ-18 conforms to the UIC prototype and has 18 circle pad blocks. The Hexa-18 and Tri-18 vary pad shape to hexagon and triangle while keep pad block numbers unchanged. The Tri-10 and Tri- 6 remain pad shape in triangle but increase the pad size and decrease the number of pad blocks. All the five designs are already in practical or experimental use.

The model meshed in COMSOL software for transient heat transfer analysis at first, then disc thermal stress was obtained from static structure analysis. The thermal stress calculation was based on the selected specific time temperature field imported from the aforesaid transient heat analysis.

\subsection{Governing Equations and Boundary Conditions}

The heat source between the disc and the pads is the train's kinetic energy. The mass per disc is $4,000 \mathrm{~kg}$, the train runs at $300 \mathrm{~km} / \mathrm{h}$, and the total energy needs to scatter by brake pair is $13.5 \mathrm{MJ}$. The wheel diameter is $0.89 \mathrm{~m}$, the disc angular speed $\left(\omega_{0}\right)$ is $187.3 \mathrm{rad} / \mathrm{s}$. The frictional heat power:

$\omega=\omega_{0}+\mathrm{a} t$

$\tau=F r_{e}=\mu F_{B} r_{e}$

$P=\tau \omega$

where $\omega$ is wheel angular speed $(\mathrm{rad} / \mathrm{s}), a$ is angular deceleration $\left(\mathrm{rad} / \mathrm{s}^{2}\right), \tau$ is torque $(\mathrm{Nm}), t$ is time (s). Assume brake with a constant brake force $\left(F_{B}\right)$ as $15 \mathrm{kN}$, the constant friction coefficient $(u)$ is 0.4 . The braking radius $\left(r_{e}\right)$ location is $0.250 \mathrm{~m}$. The frictional heat power $P(\mathrm{~W})$ is then only proportional to $\omega$ since $\tau$ is const in this scenario.

The heat fluxes at the upside $(u)$ and downside $(d)$ of the thermal contact depend on the temperature $(T)$ difference according to the following relations:

$-n_{d} \cdot\left(-k_{d} \nabla T_{d}\right)=-h_{j}\left(T_{u}-T_{d}\right)+r Q_{f}$ $-n_{u} \cdot\left(-k_{u} \nabla T_{u}\right)=-h_{j}\left(T_{d}-T_{u}\right)+(1-r) Q_{f}$

the heat partition coefficient

$$
r=\frac{1}{1+\sqrt{\frac{\rho_{u} C_{p, u} k_{u}}{\rho_{d} c_{p, d^{k} d}}}}
$$

and the joint conductance

$h_{j}=h_{c}+h_{g}$

where $h_{c}$ is the constriction conductance, use cooper mikic yovanovich correlation [25], $h_{c}=36,230 \mathrm{~W} /\left(\mathrm{m}^{2} \cdot \mathrm{k}\right)$; the gap conductance, $h_{g}=0 \mathrm{~W} /\left(\mathrm{m}^{2} \cdot \mathrm{k}\right)$. The eq. 4 and eq. 5 correspond to the heat flux of disc (downside) and pads (upside) respectively. The $Q_{f}$ is the frictional heat source equals to $P$, mean heat flux is $P / A\left(\mathrm{~W} / \mathrm{mm}^{2}\right), A$ is the frictional area $\left(\mathrm{mm}^{2}\right)$ of pads.

The convective heat flux:

$-n \cdot(-k \nabla T)=h\left(T_{a m b}-T\right)$

treats as forced air convection [25], air pressure $P_{\text {air }}$ is $1 \mathrm{~atm}$, and air temperature $T_{a m b}$ is $22{ }^{\circ} \mathrm{C}$, the heat transfer coefficient $h$ is correlation of:

$h=\left\{\begin{array}{c}2 \frac{k}{L} \frac{0.3387 \operatorname{Pr}^{1 / 3} \operatorname{Re}_{L}^{1 / 2}}{\left(1+(0.0468 / \operatorname{Pr})^{2 / 3}\right)^{1 / 4}} \operatorname{Re}_{L} \leq 5 \cdot 10^{5} \\ 2 \frac{k}{L} \operatorname{Pr}^{\frac{1}{3}}\left(0.037 \operatorname{Re}_{L}^{4 / 5}-871\right) \operatorname{Re}_{L}>5 \cdot 10^{5}\end{array}\right.$

where $\operatorname{Pr}=\mu C_{p} / k$ and $R e_{L}=\rho U L / \mu$ [25], $L$ is the disc radius, $U$ is translation speed.

The surface to ambient radiation heat flux:

$-n \cdot(-k \nabla T)=\varepsilon \sigma\left(T_{a m b}^{4}-T^{4}\right)$

represents the radiative effect of heat scatter into the surrounding air. Where the emissivity $\varepsilon$ of disc is 0.3 , and $\varepsilon$ of pad is $0.6, \sigma$ is Stefan-Boltzmann constant.

In the quasi-static analysis for calculating disc thermal expansion stress, the internal disc thermal strain caused by internal temperature changes as: 
$\epsilon_{t h}=\alpha\left(T-T_{a m b}\right)$

$\delta=\epsilon_{t h} \cdot E$

the $\alpha$ is coefficient of thermal expansion of disc material and reference surrounding temperature is $22^{\circ} \mathrm{C}, E$ is Young's modulus.

The brake time is $95 \mathrm{~s}$ (eq. 1) and simulation time for the transient heat transfer analysis is $100 \mathrm{~s}$.

\subsection{Numeral Simulations}

Brake disc gets hot quickly, and its temperature is a function of the complex interaction between conduction, radiation, and convective cooling to the surrounding air [4]. In COMOSL terms [26]. The purely heat transfer in disc and pad as:

$\rho C_{p} \frac{\partial T}{\partial t}+\nabla \cdot(-k \cdot \nabla T)=Q$

where $k$ is thermal conductivity, $\rho$ is density, $C_{p}$ is specific heat capacity. $Q$ is heat source (eq. 4 and eq. 5).

On solid domains the total heat flux variable (tflux) corresponds to sum of the normal conductive and translational heat flux (eq. 13).

tflux $=d f l u x+\operatorname{trlflux}$

The normal conductive heat flux variable (dflux) is evaluated using the temperature gradient and the effective thermal conductivity.

$d f l u x=-k \nabla T$

The disc is rotating during the braking procedure, translational heat flux for solid domains (trlflux) is defined using the internal energy $(E)$ with velocity field.

$\operatorname{trlflux}=\rho u E=\rho u C_{p} T$

where $u$ is velocity vector.

The boundary convective heat flux variable (chflux) is defined as the contribution from the convective heat flux boundary condition (eq. 8). With a geometry and time integral of chflux variable, we can examine the convective cooling as:

$P_{c}(t)=\int_{A} \operatorname{chflux}(t) \cdot d A$

$Q_{c}(t)=\int_{0}^{t} P_{c}(t) \cdot d t$

The convective heat power $\left(P_{d, c}, P_{p, c}\right)$ is the integral of chflux variable over all external boundaries of disc (notation $d$ ) or pad (notation $p$ ) at each time step. Convective heat $\left(Q_{d, c}, Q_{p, c}\right)$ is the integral of convective heat power over the time.

Similarly, on exterior boundaries, the radiative heat flux variable (rflux) accounts for the surface to ambient radiative flux (eq. 10). The radiative heat source can be described as:

$P_{r}(t)=\int_{A} \operatorname{rflux}(t) \cdot d A$

$Q_{r}(t)=\int_{0}^{t} P_{r}(t) \cdot d t$

The radiative heat power $\left(P_{d, r}, P_{p, r}\right)$ is the integral of rflux variable over all external boundaries at each time step.
Radiative heats $\left(Q_{d, r}, Q_{p, r}\right)$ is the integral of radiative heat power over the time.

The total net heat power variable (ntfluxInt) is the integral of total heat flux over all external boundaries. It is the sum of incoming and outgoing total heat flux through the disc and pads during braking.

$n t$ fluxint $=\int\left(\rho u C_{p} T-k \cdot \nabla T+q_{r}\right) \cdot n d \sigma$

where $q_{r}$ is radiative heat flux. The internal energy variations in time and net heat flux are balanced by external heat and work sources [26].

\section{RESULT ANALYSES AND DISCUSSION}

In the five designs, the disc volume $V_{d}$ is $5,806,800 \mathrm{~mm}^{3}$ and disc exterior surface exposed to air $A_{d}$ is $330,550 \mathrm{~mm}^{2}$. For the five pads list in Table $\mathbf{3}$, their frictional area $(A)$ ratio is $1.0: 1.0: 1.0: 1.3: 1.5$, because the pad's volume $(V)$ is $A$ multiple the pad height $(30 \mathrm{~mm})$, so the pad's volume ratio is the same value. The exterior surface of pads $\left(A_{e}\right)$ exposed to air of the five designs have a ratio of $1.32: 1.39: 1.43: 1.0$ : 1.30 .

\subsection{Convective and Radiative Dissipated Heat}

Table 4 shows that convective heat $\left(Q_{d, c}\right)$ and radiative heat $\left(Q_{d, r}\right)$ of the disc are proximity to each design, the difference between maximum (Hexa-18) and minimum (Tri10) value is less than $10 \%$. During the first period, the disc is under extreme high speed sliding condition, while the speed ( $U$ in eq. 9) decreases, the convective cooling flux (chflux) starts to decline. Illustrate in Fig. (3), the disc convective heat $\left(P_{d, c}\right)$ increases rapidly in the first $30 \mathrm{~s}$ and then slope drop down. $P_{d, c}$ value of Tri-10 is the lowest and $P_{d, c}$ value of Hexa-18 is the highest.

Disc radiative heat $\left(P_{d, r}\right)$ increases during braking until the disc peak temperature reached (Fig. 5), it propagate with the temperature difference to the air (eq. 10), these curves are also accordingly coincided to the disc temperature trends (Fig. 7).

Lists in Table 4, convective heat $\left(Q_{p, c}\right)$ and radiative heat $\left(Q_{p, c}\right)$ of pads are proportional to its exterior surface. The ratios are conformed to their exterior surface ratio. Pad convective power ( $P_{p, c}$, Fig. 2) and radiative heat ( $P_{p, r}$. Fig. 4) demonstrate the identical trends as above mentioned disc. The reasons are also the same. But due to the difference of pads volume $\left(V_{p}\right)$ and exterior surface $\left(A_{e}\right)$ are considerable, the difference of pads thermal filed is more significant.

\subsection{Pad Volume Factor}

Under a given amount of heat source $(Q)$ will achieve the temperature change as below,

$\Delta T=\frac{Q}{\rho \cdot V \cdot C_{p}}$

where $V$ is volume, $\rho$ is density, $C_{p}$ is specific heat capacity. $Q$ is heat source.

The pad volume shows a great influence on the maximum temperature of pad (eq. 22). Pad with big volume has higher thermal capacity and will result a lower 
Table 4. List of thermal field variables and temperature value of the disc and the pads.

\begin{tabular}{|c|c|c|c|c|c|c|}
\hline Shape & Var & Circ-18 & Hexa-18 & Tri-18 & Tri-6 & Tri-10 \\
\hline \hline Disc convective heat, J & $Q_{d, c}$ & 639,984 & 643,761 & 635,442 & 618,241 & 610,428 \\
\hline Pads convective heat, J & $Q_{p, c}$ & 158,954 & 166,166 & 171,119 & 118,207 & 150,239 \\
\hline Disc radiative heat, J & $Q_{d, r}$ & 175,040 & 170,960 & 167,721 & 169,040 & 158,249 \\
\hline Pads radiative heat, J & $Q_{p, r}$ & 141,551 & 140,510 & 146,406 & 114,126 & 126,418 \\
\hline Total dissipated heat, MJ & $Q_{d i s s}$ & 1.11 & 1.12 & 1.12 & 1.02 & 1.04 \\
\hline Dissipated / total heat, $\%$ & & 8.0 & 8.0 & 8.0 & 7.3 & 7.5 \\
\hline Disc temperature max. ${ }^{\circ} \mathrm{C}$ & & 668 & 669 & 663 & 650 & 631 \\
\hline Pads temperature max. ${ }^{\circ} \mathrm{C}$ & & 724 & 722 & 707 & 686 & 660 \\
\hline
\end{tabular}

temperature. Convective and radiative cooling ability are proportional to the temperature difference with the surrounding air (eq. 8, eq. 10). Heat conduction from pads to disk at the frictional surface also related to the temperature difference between the pad and disc. Shows in Table 4, Tri10 design has the minimum temperature, followed by Tri-6 design, and Circ-18, Hexa-18 and Tri-18 designs have 10\% greater value.

\subsection{Total Dissipated Heat}

The total dissipated heat $\left(Q_{\text {diss }}=Q_{d, c}+Q_{d, r}+Q_{p, c}+Q_{p, r}\right)$ represents the heat emitted to the air by convective and radiative during braking. The total dissipated heat is less than $8 \%$ of the total energy (i.e. $13.5 \mathrm{MJ}$ kinetic energy). It means most kinetic energy has been transformed into internal energy among the brake components. We can infer that when the braking simulation stopped at $100 \mathrm{~s}$, the disc and pads still needed long period to cool down.

\subsection{Total Net Heat Power}

Fig. (6) shows the total net heat power (eq. 21) of the five designs. It can reflect the equivalent disc and pads heating conditions during braking. The Tri-10 and Tri-6 designs have lower ntfluxint value, reaching time of the peak value is also late among the five deigns. We can figure out Tri-10 and Tri-6 have lower heat power, prove the numerical evidence why their temperature is lower.

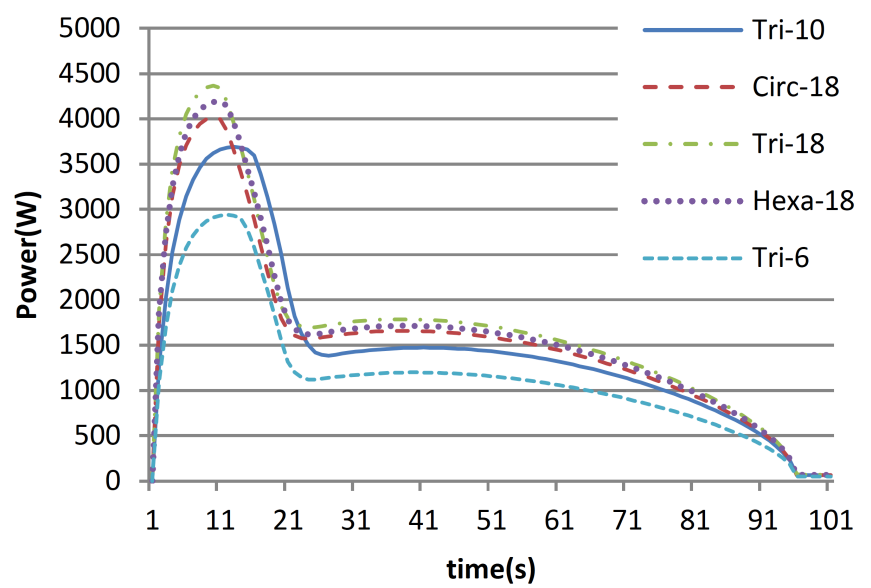

Fig. (2). Boundary convective heat power of pads.

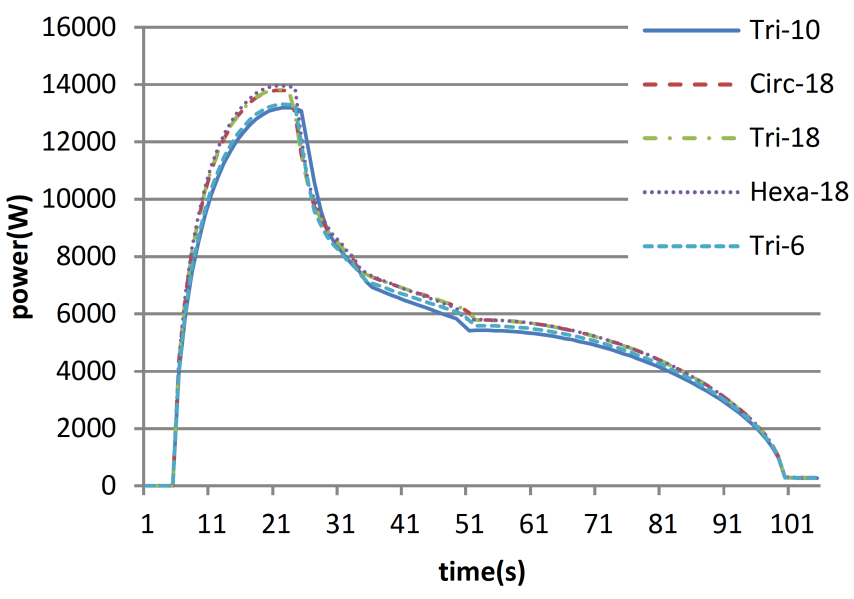

Fig. (3). Boundary convective heat power of disc.

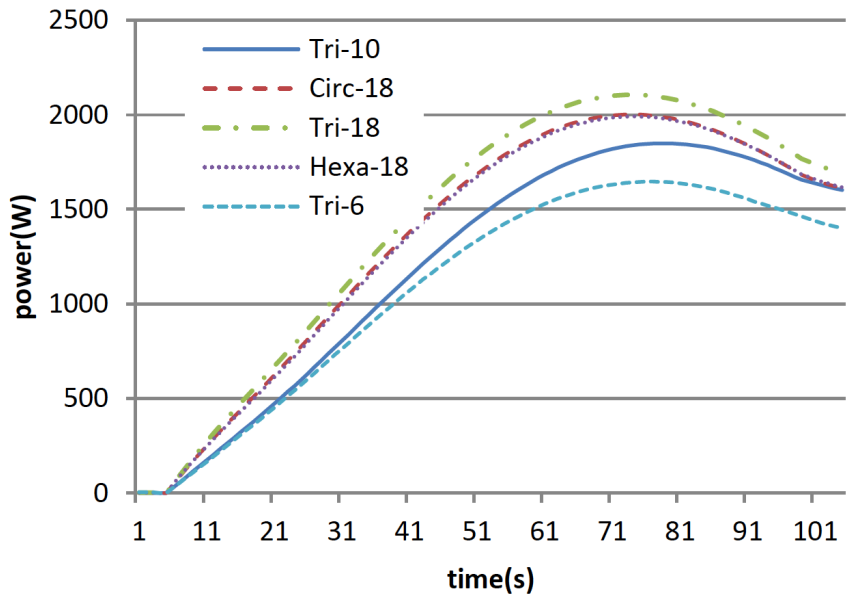

Fig. (4). Boundary radiative heat power of pads.

\subsection{Disc Temperature Field and Thermal Stress}

Thermal filed characters of the disc are similar. We just take one design for explanation. Illustrate in Fig. (7), the pad temperature rises more rapidly than the disc due to fewer thermal capacities than the disk. Pads reach peak value at about 50s. The frictional heating power declines with the speed, but the difference between maximum and minimum pad temperature is nearly constant after 10s. Disc temperature reaches its climax later at $75 \mathrm{~s}$, and the minimum disc temperature still climbs after 100s. 


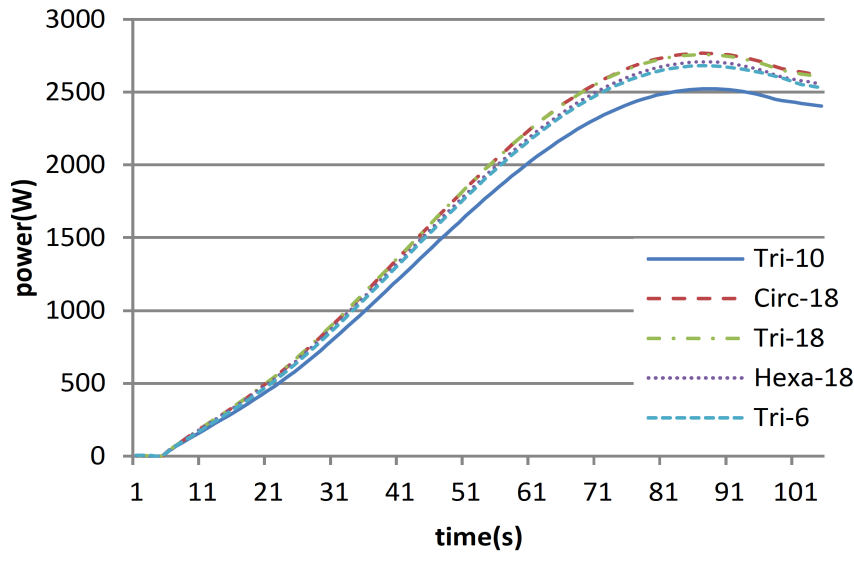

Fig. (5). Boundary radiative heat power of disc.

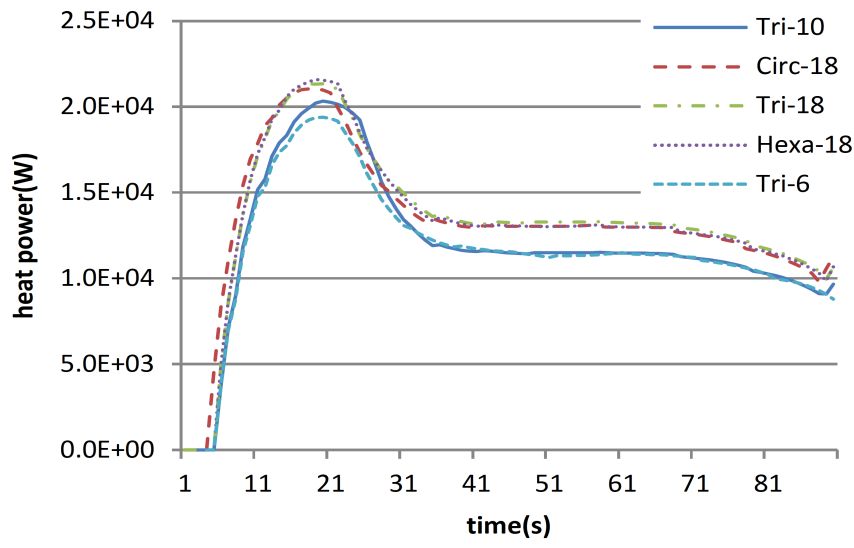

Fig. (6). Comparison of total net heat power.

The highest disc temperature difference is roughly at $75 \mathrm{~s}$, as a combined result of frictional heating to convective and radiative cooling effects. We take this time point for the disc thermal stress calculation. The disc is fully constrained when calculating its thermal expansion stress (eq. 12).

In Fig. (8) shows a linear distribution of disc temperature on the frictional surface along the radial direction during braking. Time periods are $25 \mathrm{~s}, 50 \mathrm{~s}, 75 \mathrm{~s}$ and $100 \mathrm{~s}$. The disc temperature declines from the pad's contact radius to its center and rise between the selected time periods. The temperature gradient also increases with the time. The peak temperature reaches at $75 \mathrm{~s}$.

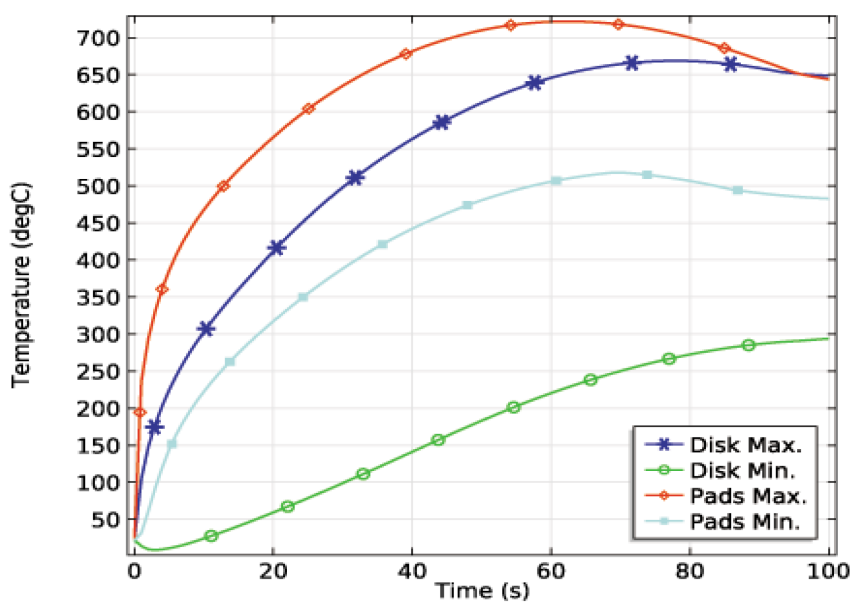

Fig. (7). Curves of max and min disc temperature and pads temperature during braking.

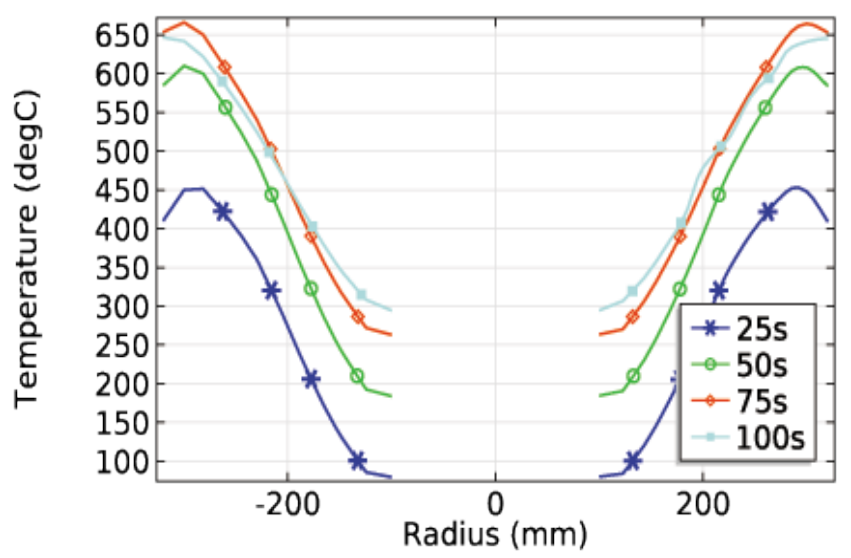

Fig. (8). Temperature distribution on disc frictional surface along radial direction at 4 selected time periods.

In Fig. (9) draws the contour of the disc thermal stress, it shows that higher thermal stress area lies on the frictional surface under the pad's contact area. Thermal stress of the disc decreases as a wave propagation pattern from the surface to internal. To focus on the frictional surface, a linear view of the disc thermal stress on the surface along the disc radial direction is presented in Fig. (10).

Table 5. Comparison of disc temperature field characters and thermal stress.

\begin{tabular}{|c|c|c|c|c|c|c|}
\hline & Var & Circ-18 & Hexa-18 & Tri-18 & Tri-6 & Tri-10 \\
\hline Peak of total heat flux, $\mathrm{W} / \mathrm{mm}^{2}$ & tflux & 31744 & 31489 & 31790 & 31277 & 30558 \\
\hline Peak of conductive heat flux, $\mathrm{W} / \mathrm{mm}^{2}$ & $d f l u x$ & 0.507 & 0.485 & 0.484 & 0.499 & 0.475 \\
\hline Disc heat flux average $\mathrm{W} / \mathrm{mm}^{2}$ & & 19,419 & 19,271 & 19,445 & 19,102 & 18,669 \\
\hline Peak value of temperature, ${ }^{\circ} \mathrm{C}$ & & 668 & 669 & 663 & 650 & 631 \\
\hline Peak value of temperature diff., ${ }^{\circ} \mathrm{C}$ & & 429.9 & 399.3 & 425.0 & 407.8 & 377.9 \\
\hline Temperature max. at $75 \mathrm{~s},{ }^{\circ} \mathrm{C}$ & & 667 & 661 & 663 & 649 & 630 \\
\hline Temperature min. at $75 \mathrm{~s},{ }^{\circ} \mathrm{C}$ & & 262 & 286 & 263 & 268 & 279 \\
\hline Temperature diff. at $75 \mathrm{~s},{ }^{\circ} \mathrm{C}$ & & 405 & 375 & 400 & 381 & 351 \\
\hline Von mises stress, $\mathrm{MPa}$ & $\delta$ & 555.8 & 489.1 & 555.3 & 533.2 & 487.1 \\
\hline
\end{tabular}




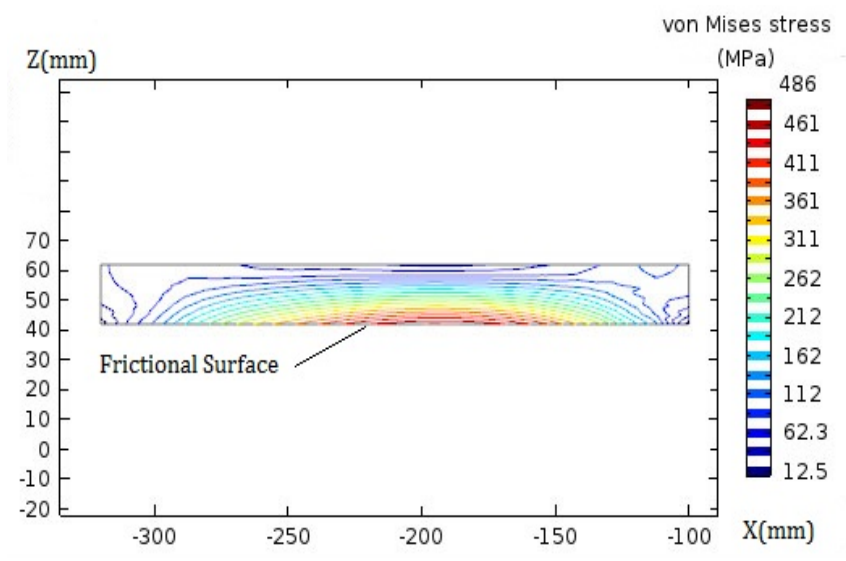

Fig. (9). Cross-section view of disc thermal stress contour.

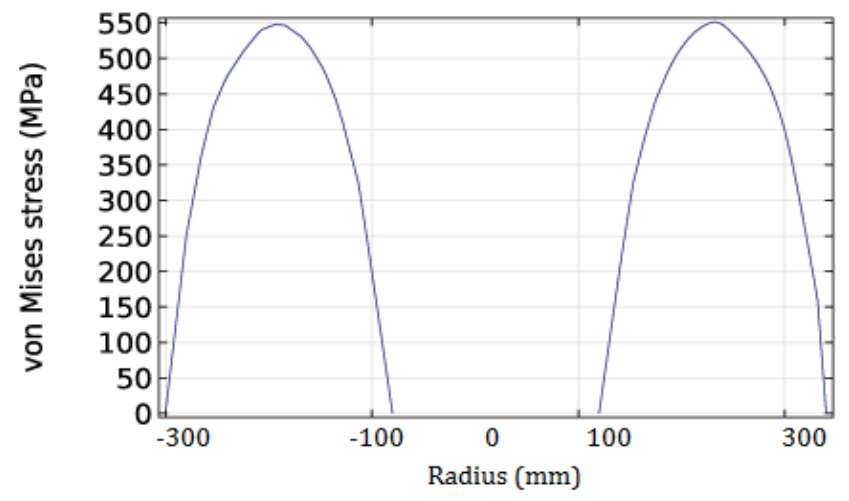

Fig. (10). Distribution of disc thermal stress along disc radius direction on the frictional surface.

From Fig. (8) and Fig. (10), we can confirm the locations of maximum temperature and peak thermal stress is not coincident. Maximum temperature is found at near outer margin whereas the peak thermal stress is found at roughly the middle between the outer and inner margin of the disc.

The braking radius is assumed at location of $0.25 \mathrm{~m}$. The outer element has a higher line speed than the inner element, so the outer frictional heat power is higher than the inner, thus makes the temperature higher at the outer margin [5]. Thermal stress is induced by thermal expansion. It is related to both temperature magnitude and temperature gradient. The disc is theoretically assumed fully fixed when obtaining the thermal stress [8]. In Fig. (8) the maximum temperature difference locates at contact radius. The contact radius is $0.25 \mathrm{~m}$, the peak thermal stress locates near the middle of disc.

Refer to Table 5, Hexa-18 and Tri-10 designs have the lower thermal stress; in contrast, the Hexa-18 design has a high-level temperature field than Tri-10 design. So Tri-10 design is the best candidate who has lower thermal stress and temperature field among the five deigns.

\section{CONCLUSION}

By the numerical simulation, we understand that convective and radiative scattered heat is only $8 \%$ of the total braking energy. Remaining energy is conducted throughout disc and pads internally during braking and heats up the brake components.
Pad volume has significant influence than pads exterior surface area on the heat dissipation progress. Variations of pad's geometry will cause a different partition ratio of convective, radiative and conductive heat of disc and pads, and introduce the dissimilarity of final temperature fields.

Pad geometry changes definitely affect the disc and pads' temperature fields, in further will change the disc thermal stress distribution. We can notice that location of the peak disc thermal stress is at the middle of the disc frictional surface while the maximum temperature of the disc is near the outer margin edge.

The Tri-10 design is an ideal candidate. The disc has minimum and uniform temperature field and less thermal stress among the five designs. The peak disc temperature of Tri-10 design is $631^{\circ} \mathrm{C}$, the peak disc thermal stress of Tri-10 design is $487 \mathrm{MPa}$.

\section{CONFLICT OF INTEREST}

The authors confirm that this article's content has no conflict of interest.

\section{ACKNOWLEDGEMENTS}

We thanks for the financial support of the Natural Science Foundation of China (Grant 51241003) and National Key Basic Research Development 973 Programs (Grant 2011CB612205).

\section{REFERENCES}

[1] A. L. Cristol-Bulthe, Y. Desplanques, and G. Degallaix, "Coupling between friction physical mechanisms and transient thermal phenomena involved in pad-disc contact during railway braking," Wear, vol. 263, pp. 1230-1242, 2007.

[2] S. Panier, P. Dufrenoy, and D. Weichert, "An experimental investigation of hot spots in railway disc brakes," Wear, vol. 256, pp. 764-773, 2004.

[3] D.-J. Kim, Y.-M. Lee, J.-S. Park, and C.-S. Seok, "Thermal stress analysis for a disk brake of railway vehicles with consideration of the pressure distribution on a frictional surface," Materials Science and Engineering: A, vol. 483, pp. 456-459, 2008.

[4] F. Talati, and S. Jalalifar, "Analysis of heat conduction in a disk brake system," Heat and mass transfer, vol. 45, pp. 1047-1059, 2009.

[5] P. Grzes, "Finite element analysis of disc temperature during braking process," Acta mechanica et automatica, vol. 3, pp. 36-42, 2009.

[6] A. Yevtushenko, and P. Grzes, "The FEM-modeling of the frictional heating phenomenon in the pad/disc tribosystem (a review)," Numerical Heat Transfer, Part A: Applications, vol. 58, pp. 207-226, 2010.

[7] M. Pevec, I. Potrc, G. Bombek, and D. Vranesevic, "Prediction of the cooling factors of a vehicle brake disc and its influence on the results of a thermal numerical simulation," International Journal of Automotive Technology, vol. 13, pp. 725-733, 2012.

[8] C. Gao, J. Huang, X. Lin, and X. Tang, "Stress analysis of thermal fatigue fracture of brake disks based on thermomechanical coupling," Journal of Tribology, vol. 129, pp. 536-543, 2007.

[9] G. Oder, M. Reibenschuh, T. Lerher, M. Sraml, B. Samec, and I. Potrc, "Thermal and stress analysis of brake discs in railway vehicles," Advanced Engineering, vol. 3, pp. 95-102, 2009.

[10] M. Eltoukhy, S. Asfour, M. Almakky, and C. Huang, "Thermoelastic instability in disk brakes: simulation of the heat generation problem," In: Excerpt from the proceedings of the COMSOL users conference, Boston, 2006.

[11] H. Qi and A. Day, "Investigation of disc/pad interface temperatures in friction braking," Wear, vol. 262, pp. 505-513, 2007. 
[12] T. P. M. Kastek, H. Polakowski, and J. Małachowski, J. Jachimowic, "Thermographics measurements and numerical simulation of a car brakes," In: Presented at the $11^{\text {th }}$ International Conference on Quantitative InfraRed Thermography, 2012.

[13] A. Adamowicz and P. Grzes, "Analysis of disc brake temperature distribution during single braking under non-axisymmetric load," Applied Thermal Engineering, vol. 31, pp. 1003-1012, 2011.

[14] A. Adamowicz, and P. Grzes, "Finite element analysis of thermal stresses in a pad-disc brake system (a review)," Acta Mechanica et Automatica, vol. 7, 2013.

[15] A. Yevtushenko, and P. Grzes, "Finite element analysis of heat partition in a pad/disc brake system," Numerical Heat Transfer, Part A: Applications, vol. 59, pp. 521-542, 2011.

[16] D. Meresse, S. Harmand, M. Siroux, M. Watremez, and L. Dubar, "Experimental disc heat flux identification on a reduced scale braking system using the inverse heat conduction method," Applied Thermal Engineering, vol. 48, pp. 202-210, 2012

[17] A. Day, M. Tirovic, and T. Newcomb, "Thermal effects and pressure distributions in brakes," Proceedings of the Institution of Mechanical Engineers, Part D: Journal of Automobile Engineering, vol. 205, pp. 199-205, 1991.

[18] P. Dufrenoy, "Two-/three-dimensional hybrid model of the thermomechanical behaviour of disc brakes," In: Proceedings of the Institution of Mechanical Engineers, Part F: Journal of Rail and Rapid Transit, vol. 218, pp. 17-30, 2004.
[19] M. Tirovic, "Energy thrift and improved performance achieved through novel railway brake discs," Applied Energy, vol. 86, pp. 317-324, 2009.

[20] A. Nejat, M. Aslani, E. Mirzakhalili, and R. Najian Asl, "Heat transfer enhancement in ventilated brake disk using double airfoil vanes," Journal of Thermal Science and Engineering Applications, vol. 3, pp. 045001-045001, 2011.

[21] M. Duzgun, "Investigation of thermo-structural behaviors of different ventilation applications on brake discs," Journal of Mechanical Science and Technology, vol. 26, pp. 235-240, 2012.

[22] K. Munisamy, N. Shuaib, M. Yusoff, and S. Thangaraju, "Heat transfer enhancement on ventilated brake disk with blade inclination angle variation," International Journal of Automotive Technology, vol. 14, pp. 569-577, 2013.

[23] J. O. O. Moses Omolayo Petinrin, "Numerical simulation of thermoelastic contact problem of disc brake with frictional heat generation," New York Science Journal, 2012.

[24] C. Sujatha, M. Nouby, and K. Srinivasan, "Reduction of automotive brake squeal through pad geometrical modifications: A numerical study," In: Frontiers in Automobile and Mechanical Engineering (FAME), pp. 393-398, 2010.

[25] F.P. Incropera, and D.P. DeWitt, Fundamentals of heat and mass transfer, $5^{\text {th }}$ ed. John Wiley \& Sons: New York, 2002.

[26] Heat Transfer Module User's Guide. Version:4.4 Nov. 2013. COMSOL A.B., 2013 (also avaiable: www.comsol.com).

(C) Jiguang and Fei; Licensee Bentham Open.

This is an open access article licensed under the terms of the Creative Commons Attribution Non-Commercial License (http://creativecommons.org/licenses/by-nc/3.0/) which permits unrestricted, non-commercial use, distribution and reproduction in any medium, provided the work is properly cited. 